This is a postprint version of the following published document:

Radl, J., Miller, L. (2021). Conceptual and Methodological Considerations on Effort: An Interdisciplinary Approach. American Behavioral Scientist, pp. 1-10.

DOI: https://doi.org/10.1177/0002764221996792

(C) 2021 The authors. 


\title{
Conceptual and methodological considerations on effort: An interdisciplinary approach
}

\author{
Jonas Radl \& Luis Miller
}

\section{Abstract}

This introduction to the special issue "Interdisciplinary Perspectives on Effort" highlights the relevance of effort as a research object and pinpoints the potential of various approaches to contribute to the advancement of knowledge on this multifaceted phenomenon. Addressing three dimensions of research - on the measurement, determinants, and consequences of effort -, the paper also gives an overview of the collection of articles in the special issue. In terms of measurement, we distinguish between self-reported invididual characteristics related to effort, on the one hand, and behavioral measures of effort referring to task performance on the other. Concerning determinants, we review the ways in which studies find incentives, personality characteristics, and family background to affect individual effort provisions. Finally, when it comes to consequences, we discuss effort as a source of legitimate entitlement to rewards, speaking to normative theories of justice, and effort as a driver of socio-economic achievement, referencing debates about the respective benefits of cognitive and non-cognitive skills. In concluding, the paper distills selected lessons learned for future research on effort.

Key words: effort, personality traits, non-cognitive skills, social justice.

\section{Introduction}

Effort is a multifaceted phenomenon that continuously engages scholarship from an array of disciplines. First and foremost, effort is a psychophysiological process, and psychologists have extensively studied the basic mechanisms behind cognitive effort (Kurzban et al. 2013; Westbrook and Braver 2015). Given the crucial importance of motivation in education, there is a large body of research on effort in learning (De Bruin 2020). In the economic literature on inequality of opportunity, effort is juxtaposed with circumstances and studied in relation with the (re)distribution of income and wealth (Andreoli and Fusco 2019) as well as educational achievement (Asadullah et al. 2021). Recent advances in behavioral economics have delved deeply into the complex workings of human effort investments, including peer effects (Dohmen and Falk 2011; Falk and Ichino 2006). Moreover, economists have long sought to understand which payment schemes incentivize maximum effort among workers (Prendergast 1999). In sociology, effort is often studied in close relation to educational expectations and attainment (Domina et al. 2011), focusing on the implications for social mobility (Farkas 2003). In occupational medicine, a strand of research investigates the effort-reward imbalance in working conditions (Siegrist et al. 2004).

In short, there is a great variety of relevant circumstances under which effort is provided, each asking for different analytical approaches. However, cross-disciplinary exchange is scarce and there is a need for knowledge consolidation regarding this elusive phenomenon. Effort is a pervasive and intuitive concept but it has been notoriously hard to capture empirically. Indeed, a 
closer look into the wide variety of empirical research addressing effort from different angles reveals a surprising lack of established evidence regarding not only its determinants and consequences but even its proper measurement and distribution in the population. This collection of articles tackles issues surrounding the measurement and contributory factors of effort, its role as moderator in skill formation and decision-making as well as its consequences for distributive preferences and socio-economic achievement.

We propose to understand cognitive effort as the mobilization of mental resources to fulfill a task. Beyond highlighting the general relevance of effort as a research object, this introduction to the special issue pinpoints the potential of interdisciplinary approaches to contribute to the advancement of knowledge on the (1) measurement, (2) determinants, and (3) consequences of effort. In doing so, this introduction also gives an overview of the articles in the special issue and distills selected lessons learned. While the individual papers go beyond the study of effort per se -they each make additional specific contributions to debates in adjacent literatures-, this schematic framework illustrates the coherence of the overall collection and outlines the contours of a larger emerging research agenda.

\section{Measurement}

Previous social research has drawn on a multitude of proxies to capture effort empirically. A key challenge in measuring effort with observational data is to discriminate between effort and capabilities. For example, behavioral indicators such as self-reported study hours (Delaney et al. 2013), employment outcomes (Kaufman and Uhlenberg 2000) or worker absenteeism (Ichino and Riphahn 2013) are flawed as effort measures because they neglect structural constraints. Recall bias is an additional source of noise. Conventional experimental studies in economics measured effort through alternative monetary choices (Fehr et al. 1998). However, this abstract form of effort consisting of a simple mouse click has been rightfully criticized as unrealistic (Levitt \& List 2007). Health economists have used lifestyle indicators such as smoking and exercise to operationalize effort (García-Gomez et al. 2015), but this approach disregards genetic dispositions and environmental influences.

Self-reported effort referring to recent learning activities (Hagger and Hamilton 2019) or subjective evaluations of effort exerted in specific tasks (Paas et al. 2003) are based on the strong assumption that people can truthfully grade their effort on a comparative scale. Alternatively, evaluations by third parties like teachers are informative (De Fraja et al. 2010). However, neither of these measures are entirely able to distinguish between ability and effort (Carbonaro 2005). One way to overcome this challenge in measuring effort, is using personality traits assessed through surveys. For example, the psychological grit scale refers to effort sustained over time (Duckworth and Gross 2014).

In the present special issue, several effort-related personality traits are closely examined. The experimental study by Aguiar, Álvarez and Miller assesses the explanatory power of the longestablished personality scale locus of control showing the stability of this measure when analyzing longitudinal data. Bortolotti, Dohmen, Lehmann, Meyer, Pignatti and Torosyan are particularly 
interested in patience, measured in various forms, both experimentally and survey-based. Holtmann, Menze and Solga examine a variety of personality characteristics, including goal pursuit as well as educational aspirations and conscientiousness as part of the Big Five personality traits. Gil-Hernández also focuses on conscientiousness as a "non-cognitive" skill and its returns. Apascaritei, Demel and Radl consider conscientiousness as well as locus of control, need for cognition and delay of gratification.

Personality traits are important individual characteristics with proven relevance for life outcomes. However, when used as a proxy of effort, personality scales are subject to significant limitations. It is well-known that the human mind is prone to take shortcuts to save energy (Tversky and Kahneman 1974) and common tendencies such as procrastination lead to disparities between rationalized views and actual behaviors (Akerloff 1991). Moreover, social desirability and moral hypocrisy may bias survey responses on self-evaluation (Lindenberg et al. 2018). In a recent set of experiments, Chen et al. (2020) show that self-reports of the Big Five personality constructs are sensitive to survey conditions, such as the positive framing of traits or rewarding respondents with status incentives for performing tasks in the same session. Insufficient effort responding to surveys has similarly been argued to introduce not only random measurement error but also systematic bias in personality studies (Huang et al. 2015). Such findings draw attention to the fact that even firmly established effort-related constructs may suffer from systematic measurement problems. Thus, effort-related self-reports ought to be distinguished from actual effort requiring the mobilization of finite resources.

Against this backdrop, behavioral measures of personality are a very promising approach. For example, Zamarro et al. (2018) propose that "survey effort" is a good proxy of established personality scales. Understanding survey responses as akin to a cognitive task, the authors demonstrate that item non-response and, especially, careless answering is significantly correlated with personality characteristics such as grit or conscientiousness. Decomposing test data from the well-known Programme for International Student Assessment (PISA), Borghans and Schils (2018) have proposed to measure students' effort as performance persistence over the two-hour test, while controlling for the difficulty of each question. Time spent answering questions is another proxy of non-cognitive traits (Soland and Kuhfeld 2019), and there is increasing evidence supporting the predictive power of such noninvasive measures of effort (Silm et al. 2020).

In summary, effort is inherently a behavior that needs to be measured objectively. In his contribution to the special issue, Palacios-Abad uses the above-mentioned persistence approach to calculate youngsters' effort as relative decline in accuracy over the test duration. Bortolotti and co-authors use a series of discrete choices between immediate and delayed rewards in a highstakes situation. The papers by Apascaritei, Demel and Radl, by De Dreu, Gërxhani and Schram and by Aguiar, Álvarez and Miller use real-effort tasks (i.e. simple tasks requiring no special ability or skill) as objective effort measures. While the former two employ different computerized tasks, the latter relies on a manual task with strong claims to ability neutrality. Moreover, De Dreu, Gërxhani and Schram collected testosterone and cortisol measures to examine whether hormonal adaptations affect cognitive effort and performance. Together, the papers in this special issue 
respond to the need for systematic research on effort and the ramifications of the methodological challenges involved with its measurement.

\section{Determinants}

Three kinds of determinants of effort are examined in this special issue: (i) incentives, (ii) personality characteristics, and (iii) family background. Effort is costly, and standard economic theory thus holds incentives to be central drivers of people's effort (Westbrook and Braver 2003). However, it has been shown that there can be a crowding out of different types of incentives (Bénabou and Tirole 2003). Adding to this literature, the contribution by De Dreu, Gërxhani and Schram to this special issue demonstrates that status incentives, and specifically the anticipation of being ranked by peers, significantly affect effort provisions, which is mediated by hormonal responses. Relatedly, Apascaritei, Demel and Radl report notable boosts in cognitive effort when material performance incentives are offered to children in the form of toys. Furthermore, it seems intuitive that not all people respond to incentives in the same way, and the evidence shown in both aforementioned papers indeed point towards stronger effects of incentives among male than among female subjects.

Not incidentally, by studying individual heterogeneity psychologists have highlighted a long list of personality traits related to effort that may help explain social differences. For example, taskrelated orientations are captured by constructs like conscientiousness, need for cognition and industriousness, and relevant broader concepts like locus of control, self-efficacy or delay of gratification. Such constructs have sometimes been used as proxies of effort (e.g. Breen and Goldthorpe 2001) but are arguably better understood as determining factors of effort to the extent that they moderate individuals' susceptibility to different incentives to exert effort.

Using a sample of $5^{\text {th }}$ graders in Spain, Apascaritei, Demel and Radl ask to what extent selfreported personality traits that are theoretically relevant for effort (subjective measures) predict the actual cognitive effort provided to complete actual tasks (objective effort). Their key result is that the explanatory power of established personality measures is disappointingly low. Although each personality scale is supposed to capture certain additional aspects, the theoretical constructs all have direct meaning for effort, suggesting closer associations with real effort provisions than could be observed empirically. Similarly, in the experimental evidence reported by Bortolotti and co-authors, empirical findings depend on whether patience is measured using hypothetical scenarios in a survey or via consequential choices in an incentivized setting.

Going back to theories of social justice, another plausible source of heterogeneity in effort is family background, raising uncomfortable questions about the degree of social fluidity of contemporary societies. Despite powerful narratives like the "culture of poverty" thesis, the evidence on the influence of parental background on effort or related constructs is scattered and, again, appears sensitive to the chosen measures. Looking at German children at different ages, both the studies by Gil-Hernández and by Holtmann, Menze and Solga show positive associations between parental socio-economic status (SES) and non-cognitive skills or personality, but both agree that this relationship is much weaker than for cognitive skills or competences. The theoretical 
considerations and new findings in these studies point to a complex interplay between ability and effort that deserves greater scholarly attention going forward.

\section{Consequences}

Significantly, effort is of key interest in fundamental debates about meritocracy and social inequality. Hence, two important consequences of effort have been discussed across the social sciences: (i) effort as a source of legitimate entitlement to rewards, speaking to normative theories of justice, and (ii) effort as a determinant of socio-economic achievement, chiefly within the debates about the benefits of cognitive and non-cognitive skills. These two types of consequences of effort - normative and factual - are discussed by different articles in the special issue.

With respect to the first dimension regarding entitlement, most people agree with the general notion that hard work helps one get ahead in life (Mijs 2019). According to the meritocratic principle, individual educational and economic achievements are determined on the one hand by people's ability and, on the other hand, by their effort. However, this 'rhetoric of rising' (Sandel 2020 ) is based on flawed assumptions of a level playing field, and backed with regrettably scant empirical evidence. From a normative point of view, according to John Roemer's (1998) theory of equality of opportunity, effort is the sole legitimate source of inequality, and most political discourses champion a view that hard work should be rewarded. In contrast, according to Rawls' (1971) theory of justice, neither effort nor merit or other individual capacities can be considered as allocation principles because we lack full control of them.

Addressing these complex philosophical questions, many experimental studies in social psychology, sociology, political science and economics have investigated whether people reward effort and productivity when they make distributive justice judgments (Cook and Hegtvedt, 1983; Frohlich et al. 2004; Konow 2003). In controlled laboratory settings, some of these studies have tried to separate the effects of effort and related concepts such as ability and productivity in justice judgments and decisions. In this special issue, Aguiar, Álvarez and Miller report the results of a real-effort experiment in which people who show an internal locus of control are significantly more likely (than people with an external locus) to accept both arbitrary and effort-based inequalities, although they accept the latter more often.

With regard to the second consequence, effort as a determinant of achievement, numerous empirical studies have examined the distinct effects of effort-related measures such as selfcontrol on life outcomes (e.g. Moffitt et al 2011; Duckworth and Gross 2014; Borghans et al. 2016). This scholarship demonstrates that findings strongly depend on the exact measures chosen. Moreover, although effort is a positive contributing factor in the attainment process, the relationship is not as simple as an additive or even multiplicative model in interaction with ability would suggest. For instance, a very recent article in educational psychology argues that it is not per se how much effort is put forth that matters for learning, but in what activities cognitive effort is invested (Dunlosky et al. 2020). In this special issue, Bortolotti and co-authors use economic incentives to explore the mediating effect of cognitive effort on the relationship between patience and cognition. 
Building onto the body of existing evidence, the paper by Palacios-Abad in this issue underlines the importance of effort for educational success. His analysis of Australian data shows that persistence measured at age 15 is a significant and relevant predictor of tertiary educational attainment ten years later. Moreover, educational expectations emerge as the driving force that, by shaping the level of effort exerted, boosts the long-term chances of college completion.

The contribution by Holtmann, Menze and Solga to the present issue analyzes the effects of multiple personality and behavioral traits - as potential mediators and moderators - on the intergenerational transmission of educational attainment in Germany. Compared to cognitive skills, the authors show that "non-cognitive skills" work more as moderators and less as mediators of the transmission of advantage across generations. Similarly, the article by Gil-Hernández tackles the interplay of parental background, cognitive and non-cognitive skills in the transition to the academic track in Germany. He finds that, when cognitive skills are limited, the benefits from being conscientious are notably higher among children from higher SES families. In other words, having a positive disposition towards effort only seems to pay off for low-performing children from advantaged social origins, but not for low-performing children from working-class origins. Both contributions to the special issue point to inequality-enhancing effects in the interaction between family background and non-cognitive skills, significantly adding to our understanding of educational mobility.

\section{Implications for future research}

The arguments and findings in this special issue have important implications for future research on effort and related concepts. Methodologically, the papers provide new evidence that holds relevance for specialists in survey design, behavioral economics, as well as psychophysiology. Sociologists and social psychologists studying personality traits, experimental economists using real-effort tasks and educational researchers interested in boosting motivation among children are just some of the audiences that we hope can be inspired by the contributions made by the 20 collaborators that make up this special issue.

In the current COVID-19 pandemic, there has been much debate about the self-control required by social distancing measures and the discipline it takes to forgo activities that used to be normal (Martarelli and Wolff 2020). At the same time, it has become apparent that the actual level of stress and sacrifice has differed immensely across social groups (Schnell and Krampe 2020). Not only because there is massive variation in resources that shape our capacity to cope with the repercussions of the pandemic, for instance with homeschooling (Bol 2020), but also because there are vastly different baselines in the activities we would undertake normally. In short, the effort it takes for each person to adapt to the new situation varies enormously, and in ways that cannot be mapped along a single continuum. Effort has remained an elusive phenomenon precisely because of the moving baseline set by people's capacities, be it in the realms of health, education, income or employment. 
Advancing knowledge on effort through better understanding the measurement issues involved, the manifold contributing factors, as well as its diverse implications, has substantial applied benefits. For example, the every-day work of educational practitioners can be enhanced by new insights on effort stimulation. How to evoke students' motivation to apply effort to learning is one of the fundamental challenges for teachers at all levels of the education system. Policy-makers can learn how to design better rules and regulations in areas where effort is a central matter, such as unemployment benefits and social assistance schemes. Finally, unraveling the twisted ways in which effort contributes to socio-economic attainment, and people's perceptions of social justice, is key for progress towards more cohesive and fair societies.

\section{References}

Akerlof, G. A. (1991). Procrastination and obedience. American Economic Review, 81(2), 1-19.

Andreoli, F., \& Fusco, A. (2019). Robust cross-country analysis of inequality of opportunity. Economics Letters, 182, 86-89.

Asadullah, M. N., Trannoy, A., Tubeuf, S., \& Yalonetzky, G. (2021). Measuring educational inequality of opportunity: pupil's effort matters. World Development, 138, 105262.

Bénabou, R., \& Tirole, J. (2003). Intrinsic and Extrinsic Motivation. The Review of Economic Studies, 70(3), 489-520.

Bol, T. (2020). Inequality in homeschooling during the Corona crisis in the Netherlands. First results from the LISS Panel. SocArXiv Papers. Doi: 10.31235/osf.io/hf32q

Borghans, L., Golsteyn, B. H., Heckman, J. J. \& Humphries, J. E. (2016). What grades and achievement tests measure. Proceedings of the National Academy of Sciences, 113, 1335413359.

Borghans, L., \& Schils, T. (2018). Decomposing achievement test scores into measures of cognitive and non-cognitive skills. SSRN. http://dx.doi.org/10.2139/ssrn.3414156.

Breen, R., \& Goldthorpe, J.H. (2001). Class, Mobility and Merit. The Experience of Two British Birth Cohorts. European Sociological Review, 17(2), 81-101.

Cook, K. S., \& Hegtvedt, K. A. (1983). Distributive Justice, Equity, and Equality. Annual Review of Sociology, 9, 217-241.

Chen, Y., Feng, S., Heckman, J. J., \& Kautz, T. (2020). Sensitivity of self-reported noncognitive skills to survey administration conditions. Proceedings of the National Academy of Sciences, 117(2), 931-935. https://doi.org/10.1073/pnas.1910731117

De Bruin, A. B., Roelle, J., Carpenter, S. K., \& Baars, M. (2020). Synthesizing cognitive load and self-regulation theory: a theoretical framework and research agenda. Educational Psychology Review, 32, 903-915.

De Fraja, G., Oliveira, T., \& Zanchi, L. (2010). Must try harder: Evaluating the role of effort in educational attainment. The Review of Economics and Statistics, 92(3), 577-597.

Delaney, L., Harmon, C., \& Ryan, M. (2013). The role of noncognitive traits in undergraduate study behaviours. Economics of Education Review, 32, 181-195.

Dohmen, T., \& Falk, A. (2011). Performance pay and multidimensional sorting: Productivity, preferences, and gender. The American Economic Review, 101(2), 556-590 
Domina, T., Conley, A., \& Farkas, G. (2011). The Link between Educational Expectations and Effort in the College-for-all Era. Sociology of Education, 84(2), 93-112.

Duckworth, A., \& Gross, J. J. (2014). Self-control and grit: Related but separable determinants of success. Current Directions in Psychological Science, 23(5), 319-325.

Dunlosky, J., Badali, S., Rivers, M. L., \& Rawson, K. A. (2020). The Role of Effort in Understanding Educational Achievement: Objective Effort as an Explanatory Construct Versus Effort as a Student Perception. Educational Psychology Review, 32, 1163-1175.

Falk, A., \& Ichino, A. (2006). Clean evidence on peer effects. Journal of Labor Economics, 24(1), 39-57.

Farkas, G. (2003). Cognitive Skills and Noncognitive Traits and Behaviors in Stratification Processes. Annual Review of Sociology, 29, 541-562.

Fehr, E., Kirchler, E., Weichbold, \& Gächter, S. (1998). When Social Norms Overpower Competition: Gift Exchange in Experimental Labor Markets. Journal of Labor Economics, 16(2), 324-351.

Frohlich, N., Oppenheimer, J., \& Kurki, A. (2004). Modelling Other-Regarding Preferences and an Experimental Test. Public Choice, 119, 91-117.

García-Gómez, P., Schokkaert, E., Van Ourti, T. \& Bago D'Uva, T. (2015). Inequity in the face of death. Health Economics, 24, 1348-1367.

Hagger, M. S., \& Hamilton, K. (2019). Grit and self-discipline as predictors of effort and academic attainment. British Journal of Educational Psychology, 89(2), 324-342.

Huang, J. L., Liu, M., \& Bowling, N. A. (2015). Insufficient effort responding: Examining an insidious confound in survey data. Journal of Applied Psychology, 100(3), 828-845.

Ichino, A., \& Riphahn, R. T. (2005). The effect of employment protection on worker effort: Absenteeism during and after probation. Journal of the European Economic Association, 3(1), 120-143.

Kaufman, G., \& Uhlenberg, P. (2000). The Influence of Parenthood on the Work Effort of Married Men and Women. Social Forces, 78(3), 931-947.

Konow, J. (2003). Which is the fairest one of all? A positive analysis of justice theories. Journal of Economic Literature, 41 (4), 1188-1239.

Kurzban, R., Duckworth, A., Kable, J. W., \& Myers, J. (2013). An opportunity cost model of subjective effort and task performance. Behavioral and Brain Sciences, 36(6), 661-679.

Levitt, S.D., \& List, J.A. (2007). What Do Laboratory Experiments Measuring Social Preferences Reveal about the Real World? The Journal of Economic Perspectives, 21(2), 153-174.

Lindenberg, S., Steg, L., Milovanovic, M., \& Schipper, A. (2018). Moral hypocrisy and the hedonic shift: A goal-framing approach. Rationality and Society, 30(4), 393-419.

Martarelli, C., \& Wolff, W. (2020). Too bored to bother? Boredom as a potential threat to the efficacy of pandemic containment measures. Humanities and Social Science Communications, 7, 28. https://doi.org/10.1057/s41599-020-0512-6.

Mijs, J. J. (2019). The paradox of inequality: income inequality and belief in meritocracy go hand in hand. Socio-Economic Review. Published 23 January 2019. https://doi.org/10.1093/ser/mwy051 
Moffitt, T. E., Arseneault, L., Belsky, D., Dickson, N., Hancox, R. J., Harrington, H., ... \& Sears, M. R. (2011). A gradient of childhood self-control predicts health, wealth, and public safety. Proceedings of the National Academy of Sciences, 108(7), 2693-2698.

Rawls, J. (1971). A theory of justice. Oxford: Oxford University Press.

Paas, F., Tuovinen, J.E., Tabbers, H., \& Van Gerven, P.W.M. (2003). Cognitive Load Measurement as a Means to Advance Cognitive Load Theory. Educational Psychologist, 38(1), 63-71.

Prendergast, C. (1999). The Provision of Incentives in Firms. Journal of Economic Literature, 37(1), 7-63

Roemer, J.E. (1998). Equality of Opportunity. Cambridge: Harvard University Press.

Sandel, M. J. (2020). The Tyranny of Merit: What's Become of the Common Good? London: Penguin.

Schnell, T., \& Krampe, H. (2020). Meaning in Life and Self-Control Buffer Stress in Times of COVID-19: Moderating and Mediating Effects With Regard to Mental Distress. Frontiers in Psychiatry, 11, 983.

Siegrist, J., Starke, D., Chandola, T., Godin, I., Marmot, M., Niedhammer, I., \& Peter, R. (2004). The measurement of effort-reward imbalance at work: European comparisons. Social Science \& Medicine, 58(8), 1483-1499.

Silm, G., Pedaste, M., \& Täht, K. (2020). The relationship between performance and test-taking effort when measured with self-report or time-based instruments: A meta-analytic review. Educational Research Review, 31, 100335.

Soland, J., \& Kuhfeld, M. (2019). Do Students Rapidly Guess Repeatedly over Time? A Longitudinal Analysis of Student Test Disengagement, Background, and Attitudes. Educational Assessment, 24(4), 327-342. https://doi.org/10.1080/10627197.2019.1645592.

Tversky, A., \& Kahneman, D. (1974). Judgment under uncertainty: Heuristics and biases. Science, 185(4157), 1124-1131.

Westbrook, A., \& Braver, T. S. (2015). Cognitive effort: A neuroeconomic approach. Cognitive, Affective, \& Behavioral Neuroscience, 15(2), 395-415.

Zamarro, G., Cheng, A., Shakeel, M. D., \& Hitt, C. (2018). Comparing and validating measures of non-cognitive traits: Performance task measures and self-reports from a nationally representative internet panel. Journal of Behavioral and Experimental Economics, 72, 51-60. 